\title{
Predictors of Timely PhD Completion: Investigating the Perceptions of PhD Candidates at the Malaysian University
}

\author{
Nurhazani Mohd Shariff
}

Azlan Zainol Abidin

Kamal Izzuwan Ramli

Rozila Ahmad

Universiti Utara Malaysia, Sintok Kedah, Malaysia

Email: hazani@uum.edu.my

\section{Doi:10.5901/mjss.2015.v6n3s1p259}

\section{Abstract}

A study was undertaken to investigate the perceptions of $P h D$ candidates at the Malaysian university regarding the predictors of timely PhD completion. Taken 320 PhD candidates from Universiti Utara Malaysia as respondents, the study focused on six predictors namely, institutional/organizational, research skill, research work, supervision, motivational and de-motivational. Research skill was perceived by the candidates as the most important predictor of timely PhD completion. The findings also revealed that the candidates perceived supervision as the second predictor of timely PhD completion, followed by motivational, de-motivational and institutional/organizational. Additionally, the PhD candidates did not perceive research work as predictor of timely completion of their $\mathrm{PhD}$. The study significantly provides the university with accurate predictors of timely PhD completion which may asssit the educators in planning and managing the postgraduate candidates specifically in terms of completing their $\mathrm{PhD}$ according to the timeframe.

Keywords: PhD candidates, timely completion, predictor, Malaysian university.

\section{Introduction}

Doctor of Philosophy, normally known as $\mathrm{PhD}$ is the highest academic degree awarded by university. As noted by Park (2005), PhD is considered as a vital discipline due to the fact that it gives rise to new knowledge, new interpretations and new explanations. Further, various stakeholders such as candidates, governments, universities, prospective employers and industry partners have increased their attention to quality research education, completion and attrition particularly for the PhD candidates. According to Grebennikov and Shah (2007), the influence of education on the national level of productivity and innovation has made the success of research students and quality of graduates an important national issue. Hence, the ultimate goal of $\mathrm{PhD}$ programs is to produce new PhDs, and efficiency is higher when the candidates graduate as soon as possible (Stock, Finegan \& Siegfried, 2009).

Today, the PhD candidates are seen as important financial sources in the Malaysian Higher Educational Institutions (HEIs) particularly the Malaysian university. Hence, the Malaysian government has given serious attention to the importance of having doctorate training program for future researchers particularly for the academicians. Realizing the important of PhD, the Ministry of Higher Education (MOHE) in the National Higher Education Strategic Plan 2020 has targeted a total of $60000 \mathrm{PhD}$ candidates by the year 2020. The major purpose is to fulfill two main objectives; to increase Malaysian income and also to increase the status of Malaysian universities (Mohamed, Ismail, Mustaffa \& Mohd, 2011). Currently, managing attrition rates and completion times of higher degree research students are key considerations for universities as they are directly tied to future funding for research places. The issue regarding timely completion of the PhD candidate which may involve longer than normal period even though it may result in successful completion of the degree has been the main focused of government, universities and doctorate candidates themselves. Hence in the case of Malaysia, it is important to study the candidates' perceptions on predictors of timely PhD completions as they significantly present the quality of Malaysian university. 


\subsection{The case of Malaysian university}

To fulfill the Malaysian university purpose of having PhD candidates completing on time, the study focused on Universiti Utara Malaysia (UUM). The PhD program at UUM began in 1992 with the first enrolment of six candidates and in 2000, the number had increased to 30 candidates, an increment of $0.94 \%$. By the year 2013 , the number of PhD candidates enrolment is 602 indicated an increment of $18.78 \%$ (Table 1). Today, UUM consists of three colleges - College of Business (COB), College of Arts and Sciences (CAS) and College of Law, Government and International Studies (COLGIS) with each college has established its own postgraduate school. The Othman Yeop Abdullah (OYA) Graduate School of Business, Awang Had Salleh Graduate School of Arts and Sciences and Ghazali Shafie Graduate School of Government (GSGSG) are established with a purpose to effectively plan and manage the timely completion among PhD candidates.

Table 1: PhD Candidates of UUM (2013)

\begin{tabular}{|l|c|c|c|}
\hline UUM Postgraduate School & Full Time & Part Time & Total \\
\hline COB: & $\mathbf{7 2 3}$ & 189 & $\mathbf{9 1 2}$ \\
\hline OYA & 15 & 85 & 100 \\
\hline Islamic Business School & 11 & 48 & 59 \\
\hline School of Business Management & 84 & 287 & 371 \\
\hline School of Economics, Finance \& Banking & 41 & 145 & 186 \\
\hline School of Accounting & 26 & 116 & 142 \\
\hline School of Technology Management \& Logistic & 12 & 42 & 54 \\
\hline Awang Had Salleh Graduate School, CAS: & 389 & 239 & $\mathbf{6 2 8}$ \\
\hline General Studies Department & 11 & 12 & 23 \\
\hline School of Education \& Modern Languages & 141 & 113 & 254 \\
\hline School of Multimedia, Technology \& Communication & 7 & 68 & 75 \\
\hline School of Computing & 34 & 138 & 172 \\
\hline School of Quantitative Sciences & 11 & 34 & 45 \\
\hline School of Social Development & 35 & 24 & 59 \\
\hline GSGSG, COLGIS: & $\mathbf{2 2 5}$ & $\mathbf{6 2}$ & $\mathbf{2 8 7}$ \\
\hline School of Government & 31 & 80 & 111 \\
\hline School of International Studies & 16 & 62 & 78 \\
\hline School of Law & 11 & 57 & 68 \\
\hline School of Tourism, Hospitality \& Environmental Management & 4 & 26 & 30 \\
\hline TOTAL & 1337 & $\mathbf{4 9 0}$ & 1827 \\
\hline
\end{tabular}

Source: UUM Academic Affair Department (2013)

\subsection{Objective and significance of the study}

The main objective of the study was to investigate the PhD candidates' perceptions on predictors of timely completion of their study at the Malaysian university. The predictors covered six major aspects - institutional/organizational, research skill, research work, supervision, motivational and de-motivational. The study significantly would contribute to the research methodological perspective particularly to existing knowledge, concepts and research regarding the predictors of PhD timely completion specifically in the case of Malaysian university. Further, it would also contribute to effective planning of the postgraduate schools for future success of the PhD candidates.

\section{Literature Review}

The target time to complete $\mathrm{PhD}$ varies accordingly. For most PhD programs the target time to complete was five years and candidates rarely complete in three years (Stock et al., 2009). Five years target time for PhD completion is consistent with Wamala, Ocaya and Oonyu (2012) who used five years as a benchmark for PhD completion in their study. However, a study conducted in a single discipline area, Statistics in the Mathematical Sciences Discipline at Queensland University of Technology in Australia define timely completion to be within 3.5 years. The issue of skills and training of PhD candidates has been discussed in several meetings such as the Dearing Report (1996), Harris Report (1996) and 
Roberts Report (2002). Further, the issue of PhD candidates extended candidature and non-completion has also received attention in Uganda (Wamala et. al., 2012). Increasing attention has been paid to quality research education, completion and attrition by the candidates, governments, universities, prospective employers and industry partners (Bourke, Holbrook, Lovat \& Farley, 2004; Grebennikov \& Shah, 2007). According to Blackmore and Nesbitt (2008), there were number of issues which spanned the computing and business disciplines in completing PhD. They concluded that managing the attrition rates and completion times of higher degree research students are key considerations for Universities.

\subsection{Institutional/organizational}

Institutional/organizational refers to supporting physical resources and infrastructure includes car parks, lecture halls, office space and library services (Pitchforth, Beames, Thomas, Falk, Farr, Gasson, Thomprin \& Mengersen, 2012; Stock et al., 2009). It is important to facilitate students with office space as PhD candidates with office space are more likely to complete their PhD earlier compared to those without office space (Stock et al., 2009). Library services are important to enhance PhD student's experience. This includes computer access, ease of access to the library when needed, access to electronic library resources, remote access to the library catalogues, intercampus books and materials' delivery services, library staff assistance and interlibrary loan services (Grebennikov \& Shah, 2007; Pitchforth et al., 2012). According to Wamala et al. (2012) institutions need to offer solid remedial program to address academic unpreparedness of new students especially those in thesis based program. It would be helpful to the candidates when the institution conduct workshops on designing survey, data collection, data analysis and academic writing. Off campus support and conducting events that provides an avenue for networking with other research students and university research centres will also assist students throughout their candidature (Grebennikov \& Shah, 2007).

\subsection{Research skill}

According to Ssegawa and Rwelamila (2009), it is clearly established that major reasons for research students' attrition are the lack of hand-on skills in the research process especially in the research definition and design stages. They further stated that another challenging task for research students is translating the defined and designed components in the framework into an acceptable and well-written proposal. Additionally, other research skills identified are an ability to think critically, the skills necessary to plan and undertake independent study and research, and the development of the latest knowledge and skills (Grebennikov \& Shah, 2007). Based on Pitchforth et al. (2012), other skills required for timely PhD completion are incoming skills which refers to the research and management skills of the student at the time of enrolment such as time management skills, discipline expertise, English, writing and maths.

\subsection{Research work}

Many of the candidature problems are related to the expiration of the allowed period for candidature (Bourke et al., 2004). According to Latona and Browne (2001), getting started early on the thesis topic largely contributes to success. Therefore the requirement to prepare research proposal before enrolment can reduce uncertainty and help students to progress at a faster speed. Latona and Browne (2001) also suggested keeping the same topic and supervisor because evidence has shown that students are significantly slowed down by changes in topics and arrangements. Despite disciplinary differences in organizing doctoral education, Pyhalto and Helsinki (2012) found no difference in the students' sense of relational agency between faculties. Relational agency refers to candidates' capacity to work with others in order to better respond to complex research problems. It is research group status that is related to sense of relational agency. Students who carried out their thesis as a part of a research group perceived themselves as an active relational agent. This suggests that a sense of an active relational agency frequently occurred in group based setting.

\subsection{Supervision}

Problem with supervision is the reason most frequently mentioned for non-completion of $\mathrm{PhD}$ (Bourke et al., 2004). At a basic level it is also noted that more frequent supervision is strongly correlated with successful completion (Woodward, 1993). Based on Delany (2013), the characteristics of good supervisors are approachable, friendly, supportive, have positive attitude, open minded, prepared to acknowledge error, organized, thorough, stimulating, conveys enthusiasm for research. A good supervisor will play his/her role as a director, facilitator, adviser, teacher, guide, critic, freedom giver, 
supporter, friend, and a manager. It is essential to have positive relationship between students and supervisors because the quality of the interaction and personal quality of the supervisor are important predictors of timely PhD completion (Latona \& Browne; 2001).

\subsection{Motivational and de-motivational}

Students' mode of study is frequently related to financial assistance. The full-time students usually receive financial assistance and do not have major financial worries. Similar with mode of study, the influence of scholarship or financial assistance on PhD students' completion or attrition remains uncertain. Bourke et al. (2004) found that candidates who held a scholarship have shorter candidature. This is consistent with Stock et al. (2009), but only among US citizens, and not non US citizens. In contrast, Wamala et al. (2012) discovered that in Makerere, Africa students with scholarship or financial assistance are more likely to extend their candidature to more than five years. According to Kearns, Gardiner and Marshall (2008), self-handicapping behaviour makes PhD such a difficult process and prevents candidates from completing on time. Self-handicapping behaviour or self-sabotage can be defined as the process of creating obstacles to your goals for reasoning if failure occurs. The process could be real or imagined. Self-handicapping behaviours commonly displayed by PhD students are overcommitting, busyness, perfectionism, procrastination, disorganization, not putting in effort, and choosing performance-debilitating circumstances. Overcommitting can be described as taking on so many things such as part-time job or other responsibilities that completing PhD, the high priority goals suffer. Busyness refers to looking very busy getting less important things such as attending many seminars done but hardly has the time for more important tasks such as writing a draft of the first chapter.

\section{Research Methodology}

\subsection{Population and sample}

The target population of the study was the PhD candidates from all the three postgraduates' schools of UUM - OYAUUM COB, Awang Had Salleh Graduate School UUM CAS and GSGSG UUM COLGIS. The number of PhD candidates currently active for the year 2013 is 1827 . Based on the number of population previously mentioned and supported by Krejcie and Morgan (1970), a sample size of 317 - 320 would be appropriate and sufficient for such a number thus the study involved a total of 320 respondents to represent the whole population.

\subsection{Data collection}

Since the purpose of the study was to explore and examine the PhD candidates' perceptions on predictors of PhD timely completion, a self-administered survey questionnaire was used as research instrument. 320 questionnaires were distributed to the respondents by two research assistants at the Postgraduates' Rooms. The respondents were asked to fill in the questionnaire and leave it in the box provided. Within three days, the questionnaire was collected by the research assistants.

\subsection{Data analysis}

The study used Statiscal Package of Social Sciences (SPSS) Version 2007 with descriptive and inferential analysis to identify patterns and general trends in the dataset of this study. Hence, descriptive analyses such as frequency counts, percentages and cumulative percentages, the central tendency such as mean, median, mode, and standard deviation (Sekaran \& Bougie, 2009) were employed in this study to describe the candidate's background as provided by respondents.

\section{Findings and Discussion}

\subsection{The candidates' background}

The analysis of candidates' background indicated that most were male $(77.0 \%)$ whilst the remaining were female (23.0\%). Mostly, the candidates completed a Master's Degree by Research (64.0\%), followed by a Master's Degree by Coursework (6.5\%), then few candidates with a Bachelor's Degree with First Class Honors (2.2\%) and the remaining 
obtained other degree (27.3\%). The highest percentage was full time PhD candidates (92.8\%) and the remaining was part time PhD candidates (7.2\%). Majority candidates were in their second year (40.3\%), followed by first year (39.6\%), third year (7.2\%) and fourth year (3.6\%). The study also revealed that majority candidates used their own personal fund to pursue study in $\mathrm{PhD}$ (39.6\%), 33.1\% were sponsored by the government, $18.0 \%$ were sponsored by their parents/family, $2.9 \%$ were sponsored by the private institution and the remaining $6.5 \%$ were sponsored by other financial sources. The findings also showed that most candidates conducted research on the area of human resource management (18.7\%), followed by education (16.5\%), revenue management (9.4\%), marketing (8.6\%) and environmental management (1.4\%).

\subsection{Institutional/organizational}

Table 2 depicts the findings of descriptive analysis for the institutional/organizational as predictor of timely $\mathrm{PhD}$ completion. The findings indicated five items with average mean values between $3.32-3.83$. $73.4 \%$ candidates expressed natural environment of the institution played important role as predictor of timely completion of their PhD studies. $63.3 \%$ candidates also found that location of the institution is important in order for them to complete their studies on time. The findings depicted that $61.1 \%$ candidates found the institution also provide sufficient services in completing their PhD studies. Further, 56.8\% candidates found the counseling and career support provided by the institutions as predictor in determining the timely completion of their studies. However, the findings revealed that $45.3 \%$ candidates stated that the institution only conducted few workshops regarding their research work.

Table 2: Descriptive Analysis of Institutional/Organizational

\begin{tabular}{lccccc}
\hline Items & Mean & Standard Deviation & Slightly agree (\%) & Strongly agree (\%) & Total Percent \\
\hline Natural environment & 3.83 & .922 & 51.8 & 21.6 & 73.4 \\
Counseling and career support & 3.50 & 1.038 & 41.7 & 15.1 & 56.8 \\
Provide sufficient services & 3.65 & 1.075 & 38.1 & 23.0 & 61.1 \\
Location & 3.62 & 1.176 & 38.8 & 24.5 & 63.3 \\
Only few workshops & 3.32 & 1.030 & 33.1 & 12.2 & 45.3 \\
\hline
\end{tabular}

\subsection{Research skill}

Table 3 depicts eight items of research skill as predictor of PhD timely completion with average mean values between $3.91-4.26$. The findings significantly found that candidates agreed that thinking skill is the most important predictor of timely completion of their thesis (84.9\%). This is followed by the research skill (80.6\%) and the decision making skill (79.2\%). Additionally, the candidates felt that interpersonal skill (77.7\%) and oral communication skill also contributed to their completion of PhD studies. They also stressed that PhD graduates must possess the technical writing skill to complete their PhD studies (75.5\%). The findings revealed that PhD graduates must work independently in conducting their thesis and must not totally rely on their supervisors (72.0\%). Further, multi-task work skill was seen as the least skill they need to have in conducting their PhD studies with only $69.8 \%$ candidates agreed it did not played important role as predictor in determining the timely completion of their PhD studies.

Table 3: Descriptive Analysis of Research Skill

\begin{tabular}{lccccc}
\hline Items & Mean & Standard Deviation & Slightly agree (\%) & Strongly agree (\%) & Total Percent \\
\hline Thinking skill & 4.26 & .935 & 35.3 & 49.6 & 84.9 \\
Research skill & 4.12 & .993 & 39.6 & 41.0 & 80.6 \\
Decision making skill & 4.12 & .925 & 39.6 & 39.6 & 79.2 \\
Interpersonal skill & 4.12 & .956 & 36.0 & 41.7 & 77.7 \\
Technical writing skill & 4.10 & 1.031 & 30.9 & 44.6 & 75.5 \\
Work independently & 4.04 & .904 & 35.3 & 36.7 & 72.0 \\
Oral communication skill & 4.02 & .981 & 40.3 & 36.0 & 76.3 \\
Multi-task work skill & 3.91 & .962 & 39.6 & 30.2 & 69.8 \\
\hline
\end{tabular}




\subsection{Research work}

The findings showed that research work derived as insignificant predictor of timely PhD completion. Table 4 depicts the moderate mean values for all the four items. $65.5 \%$ candidates stated that they received prompt feedbacks from the supervisor regarding their research work. In fact, $59.7 \%$ candidates felt that literature search played important role in completing their $\mathrm{PhD}$ thesis. Further, 51.8\% candidates indicated that they could write a clear and concise research report. However, $51.7 \%$ candidates found difficulty in identifying the topic of their thesis particularly at the beginning of writing their proposal.

Table 4: Descriptive Analysis of Research Work

\begin{tabular}{lccccc}
\hline Items & Mean & Standard Deviation & Slightly agree (\%) & Strongly agree (\%) & Total Percent \\
\hline Receive prompt feedbacks & 3.74 & .961 & 44.6 & 20.9 & 65.5 \\
Literature search & 3.59 & .970 & 44.6 & 15.1 & 59.7 \\
Problem identifying the topic & 3.44 & 1.040 & 38.8 & 12.9 & 51.7 \\
Write a clear and concise research report & 3.46 & .950 & 39.6 & 12.2 & 51.8 \\
\hline
\end{tabular}

\subsection{Supervision}

Table 5 depicts the findings of supervision as predictor of PhD timely completion. The study indicated 12 items of supervision with average mean above $0.3 .78 .4 \%$ candidates expressed their supervisors as wise and knowledgeable, $76.2 \%$ frequently consult their supervisors and $75.5 \%$ rated their supervisors as helpful in guiding them in completing their PhD. Further, $73.4 \%$ candidates stated their supervisors as very committed and well-known academician. More, $72.0 \%$ candidates found their supervisors to be critical and constructive in providing feedback regarding their thesis. The findings also found that $71.2 \%$ candidates indicated that their supervisors had many research students and $66.9 \%$ candidates indicated that their superviors were able to provide feedback on time. Additionally, $66.2 \%$ candidates had supervisors who were recommended by their friends and $64.1 \%$ of their supervisors had vast experiences in supervising postgraduate students. Further, the findings found that $64.1 \%$ candidates relied on their supervisors for completing their PhD studies whilts $64.0 \%$ candidates believed that their supervisors were available for consultation.

\subsection{Motivational}

Table 6 depicts the findings of descriptive analysis on motivational as predictor of timely PhD completion. It was noted that the average mean values derived for all the seven items was $2.72-4.01$. The findings of the survey indicated that $74.1 \%$ candidates were motivated to complete their PhD studies based on their self-fulfillment desire. Additionally, $65.5 \%$ candidates were motivated by their future career development once they have finished their PhD. Meanwhile, $61.8 \%$ candidates stated that they had to complete their $\mathrm{PhD}$ on time due to the requirement of their current jobs and similarly because of the motivation from their spouses. Further, the findings of the survey also showed that $58.3 \%$ candidates were motivated to finish up their studies due to the financial aspect. Interestingly, $57.6 \%$ candidates expressed that they need to complete their PhD on time because of its prestige degree. The findings also revealed that $51.1 \%$ candidates perceived the timely completion of $\mathrm{PhD}$ studies were important since it would be considered in their current job promotion.

Table 5: Descriptive Analysis of Supervision

\begin{tabular}{|c|c|c|c|c|c|}
\hline Items & Mean & Standard Deviation & Slightly agree (\%) & Strongly agree (\%) & Total Percent \\
\hline Wise and knowledgeable & 4.11 & .899 & 40.3 & 38.1 & 78.4 \\
\hline Frequently consult & 4.04 & .896 & 42.4 & 33.8 & 76.2 \\
\hline Helpful in guiding & 4.02 & .943 & 41.7 & 33.8 & 75.5 \\
\hline Very committed & 4.00 & .989 & 38.1 & 35.3 & 73.4 \\
\hline Well known academician & 3.94 & .946 & 43.2 & 30.2 & 73.4 \\
\hline Critical and constructive feedback & 3.92 & .909 & 43.9 & 28.1 & 72.0 \\
\hline Many research students & 3.92 & 1.043 & 36.7 & 34.5 & 71.2 \\
\hline Recommended by friends & 3.79 & .967 & 41.7 & 24.5 & 66.2 \\
\hline Vast experiences & 3.78 & 1.048 & 35.3 & 28.8 & 64.1 \\
\hline Available for consultation & 3.76 & 1.114 & 33.8 & 30.2 & 64.0 \\
\hline Timely feedback & 3.75 & 1.008 & 44.6 & 22.3 & 66.9 \\
\hline Can be relied on & 3.68 & .941 & 46.8 & 17.3 & 64.1 \\
\hline
\end{tabular}


Table 6: Descriptive Analysis of Motivational

\begin{tabular}{lccccc}
\hline Items & Mean & Standard Deviation & Slightly agree (\%) & Strongly agree (\%) & Total Percent \\
\hline Self-fulfillment & 4.01 & .989 & 37.4 & 36.7 & 74.1 \\
Career change & 3.89 & 1.032 & 31.7 & 33.8 & 65.5 \\
Prestige degree & 3.69 & 1.009 & 33.1 & 24.5 & 57.6 \\
Requirement of current job & 3.68 & 1.221 & 30.9 & 30.9 & 61.8 \\
Financial & 3.65 & 1.039 & 37.4 & 20.9 & 58.3 \\
Spouse & 3.50 & 1.204 & 42.4 & 19.4 & 61.8 \\
Promote in current job & 3.44 & 1.257 & 28.8 & 22.3 & 51.1 \\
\hline
\end{tabular}

\subsection{De-motivational}

Table 7 depicts the findings of de-motivational as predictor of timely $\mathrm{PhD}$ completion. The findings of the descriptive analysis indicated that all eight items derived with moderate mean values of $2.36-2.89$. The findings revealed that 45.0\% candidates expressed financial difficulties as a major aspect de-motivated them in completing their PhD studies. $35.0 \%$ candidates emphasized that changing institutions as another important aspect de-motivated them to complete their studies on time. The findings also depicted $32.5 \%$ candidates perceived lack of interest as another relevant aspect that de-motivated them to complete their PhD studies, followed by $30.0 \%$ candidates indicated lack of confident, $30.0 \%$ candidates indicated health problems, $25.0 \%$ candidates stated emotional stress, $22.5 \%$ candidates perceived commuting distance and $20.0 \%$ candidates indicated burnout as de-motivatinal predictors of timely PhD completion.

Table 7: Descriptive Analysis of De-motivational

\begin{tabular}{lccccc}
\hline Items & Mean & Standard Deviation & Slightly agree (\%) & Strongly agree (\%) & Total Percent \\
\hline Financial difficulties & 2.89 & 1.326 & 22.5 & 22.5 & 45.0 \\
Emotional stress & 2.79 & 1.215 & 12.5 & 12.5 & 25.0 \\
Lack of interest & 2.72 & 1.279 & 22.5 & 10.0 & 32.5 \\
Lack of confident & 2.70 & 1.311 & 15.0 & 15.0 & 30.0 \\
Commuting distance & 2.69 & 1.235 & 12.5 & 10.0 & 22.5 \\
Burnout & 2.63 & 1.242 & 7.5 & 12.5 & 20.0 \\
Change institutions & 2.52 & 1.309 & 25.0 & 10.0 & 35.0 \\
Health problems & 2.50 & 1.344 & 17.5 & 12.5 & 30.0 \\
\hline
\end{tabular}

\section{Discussion}

Research skill is strongly and significantly perceived by the candidates as a major predictor of timely $\mathrm{PhD}$ completion. The postgraduate candidates of UUM believe that research skills are very important in order to complete their studies on time for instance thinking skill, research methodology skill, independent working skill, decision making skill and technical writing skill. The study is consistent to previous studies by Mohamed et. al. (2011) and Ssegawa and Rwelamila (2009) where it is noted that lack of hand-on skills consequently contributing to the timely completion of PhD. In fact, these skills are also believed by Grebennikov and Shah (2007) to present the development of an ability to think critically, the development of the latest knowledge and further, the independent skill required for conducting research work.

Supervisor is noted to be the second predictor of timely PhD completion perceived by the candidates of UUM. Consequently, this aspect represents the quality of the supervisor which is noted to be the key factor determining the successful and timely completion of a PhD. The postgraduate candidates of UUM perceive their supervisors as wise and knowledgeable, can be frequently consult and very helpful in guiding them to complete their study. Therefore, they believe to complete PhD on time, the candidates need to have an easy access to and good communication with their supervisors. Furthermore, they also believe that having well known supervisors which in this case refer to experience and expertise particularly in the area under studied contribute to the timely completion of $\mathrm{PhD}$. The findings are consistent to previous studies by Grebennikov and Shah (2007), Dinham and Scott (1998) Knowles (1999) and Seagram, Gould and Pyke (1998).

However, the PhD candidates of UUM perceive research work as a predictor less contributing to the timely completion of their PhD. The UUM candidates believe that receiving prompt feedback regarding their work from the supervisor may not actually be the major reason for them to complete their PhD on time. In fact, they also perceive that 
an extensive literature search would not cause them to finish their work within the timeframe provided. The candidates also perceive that having problem in identifying the research topic probably is important predictor contributing to the timely completion of PhD but most candidates did not believe it is the major cause since it is only at the first phase of their study. This is supported by previous study by Seagram et al. (1998) and Mohamed et al. (2011). Hence, the issues that co-vary with field of study, such as making an early start on the dissertation and maintaining the same topic may explain the differences in completion times.

Institutional/organizational however is found to be contradicted to other previous studies such as by Bourke et al. (2004), Latona and Browne (2001) and Rodwell and Neumann (2005). Institutional is indicated as a predictor less contribution to the timely completion of $\mathrm{PhD}$ among the postgraduate candidates of UUM. The natural environment of UUM itself probably serves as an important aspect represents relaxation and enjoyment in completing the PhD degree and may probably determine the process of selecting a place to further $\mathrm{PhD}$ degree among the candidates. This is considered as a new predictor based on the fact that no study has taken into account to investigate this aspect. The candidates may be looking for a university which is able to make them feel relax in pursuing their $\mathrm{PhD}$, taking into account it may be stressful to complete the study on time. Hence, in the case of UUM, location and natural environment has strong relationship in determining the timely completion of $\mathrm{PhD}$ among the candidates.

Interestingly, motivational is considered a new predictor which has been studied in this context. Positive emotional state, continuity of study and personal circumstances are among the aspects included in the study of motivational factor in line to study by Pitchforth et al. (2012). Therefore the study of motivational as predictor of timely PhD completion contributes as a new source in the literature. The UUM candidates believe that having a strong desire to complete their $\mathrm{PhD}$ significantly motivated them to work hard. The PhD candidates of UUM also perceive the de-motivational as one of the vital aspects contributing to the timely completion of their $\mathrm{PhD}$. In line with other studies regarding PhD which emphasize the influence of financial assistance in the timely completion and attrition of PhD degree (Bourke et al., 2004; Stock et al., 2009), the candidates believe that financial difficulty is the major item de-motivating them to complete their $\mathrm{PhD}$. Further, it is noted that self-support and graduate teaching assistant posts increase the time to completion and the likelihood of non-completion of PhD (Cobb, 2013; Mohamed et al., 2011).

\section{Conclusion}

The study has explored the UUM PhD candidates' perceptions on predictors of timely PhD completion. The case refers to PhD candidates of UUM covering three major postgraduate schools namely OYA COB, Awang Had Salleh Graduate School CAS and GSGSG COLGIS. Five predictors are found to be significantly contributed to the timely completion of $\mathrm{PhD}$ among the candidates of UUM. Research skill derives as the most contributing predictor follows with supervisor, demotivational, motivational and institutional/organizational. Interestingly, research work is found to have a small contribution to the timely completion of $\mathrm{PhD}$ among the candidates of UUM hence become the insignificant predictor. The findings particularly would assist the postgraduate schools in efficiently planning and managing their PhD candidates in the future and can be applied in the other context of Malaysian university.

However, the study only focused on the candidates' perceptions on the predictors of timely PhD completions and the data used in this study only involved the postgraduate which in this case refer to the doctoral candidates who are still in the process of completing their studies. Hence, the findings may be constrained with the perceptions of doctoral candidates who have already completed their $\mathrm{PhD}$. It is recommended for future research that the candidates' characteristics should be examined in order to understand the influence of $\mathrm{PhD}$ degree completion. This would include characteristics such as age, gender, country of origin and marital status as previously conducted by Bourke et al. (2004) and Cobb (2013). Furthermore, it is also suggested that an in-depth study on motivational aspect should also be considered in other Malaysian universities since it is proven to be a new significant predictor of timely PhD completions.

\section{References}

Bourke, S., Holbrook, A., Lovat, T. \& Farley, P.(2004). Attrition, completion and completion times of PhD candidates. Paper presented at the AARE Annual Conference, Melbourne, 28 Nov - 2 Dec 2004.

Blackmore, K. L. \& Nesbitt, K. V. (2008). Identifying risks for cross-disciplinary higher degree research students. Paper Presented at Tenth Australasian Computing Education Conference (ACE2008), Wollongong.

Cobb, F. (2013). Factors affecting postgraduate research student completion rates: literature review and reflections for research. A Report Prepared for the University of East London.

Dearing Report (1996). Higher education in the learning society. London: National Committee of Inquiry into Higher Education.

Delany, D. (2013). A review of the literature on effective PhD supervision retrieved from http://www.mostlyreadingya.com/read-file/a- 
review-of-the-literature-on-effective-phd-supervision-pdf-1656319/ in 6 May 2014.

Dinham, S. \& Scott, C. (1999). The doctorate: talking about the degree, University of Western Sydney, Nepean.

Grebennikov, L. \& Shah, M. (2007). Enhancing the research student experience at university. A report submitted to the Australasian Association for Institutional Research 2008 Forum, 15 September 2007.

Harris Report (1996). Review of postgraduate education. Bristol: Higher Educational Funding Council for England.

Kearns, H., Gardiner, M. \& Marshall, K. (2008). Innovation in PhD completion: the hardy shall succeed (and be happy!). Higher Education Research \& Development, 27, 77-89.

Knowles, S. (1999). Feedback on writing in postgraduate supervision: echoes in response-context, continuity and resonance. Supervision of Postgraduate Research in Education, 113-128.

Krejcie, R. V. \& Morgan, D. W. (1970). Determining sample size for research activities. Educational and Psychological Measurement, 30, 608.

Latona, K. \& Browne, M. (2001). Higher education series: factors associated with completion of research higher degrees. Higher Education Division, Sydney.

Mohamed, A., Ismail, A. H., Mustaffa, M. M. \& Mohd, N. (2011). Factors contributing to the success of engineering doctoral students at UKM. Paper presented at the Seminar Pendidikan Kejuruteraan Kongres Pengajaran dan Pembelajaran \& AlamBina (PeKA'11) UKM 2011.

Park, C. (2005). New variant PhD: the changing nature of the doctorate in the UK. Journal of Higher Education Policy and Management, 27(2), 189-207.

Pitchforth, J., Beames, S., Thomas, A., Falk, M., Farr, C., Gasson, S., Thamrin, S.A., \& Mengersen, K. (2012). Factors affecting timely completion of a PhD: a complex systems approach. Journal of the Scholarship of Teaching and Learning, 12(4), 124-135.

Pyhalto, K. \& Keskinen, J. (2012). Doctoral students' sense of relational agency in their scholarly communities. International Journal of Higher Education, 1(2), 136-149.

Roberts Report (2002). Set for success: the supply of people with science, engineering and technology skills. London: UK Government Department of Trade and Industry and Department of Education and Skills.

Rodwell, J. \& Neumann, R. (2007). Predictors of timely doctoral student completions by type of attendance: the utility pragmatic approach. Sydney, Australia: Macquarie Graduate School of Management.

Seagram, B., Gould, J. \& Pyke, S. (1998) An investigation of gender and other variables on time to completion of doctoral degrees, Research in Higher Education, 39(3), 319-335.

Sekaran, U., \& Bougie, R. (2010). Research methods for business: a skill building aprroach (5th ed.). UK: Wiley.

Ssegawa, J. K. \& Rwelamila, P. D. (2009). The research skill factor as a cause for high postgraduate attrition rate, Journal of Engineering, Design \& Technology, 7(3), 293-322.

Stock, W. A., Finegan, T. A., \& Siegfried, J. J. (2009). Completing an economics PhD in five years: let the data literally speaks for themselves. American Economic Review: Papers and Proceedings, 99(2), 624-629.

UUM (2013). Statistics of PhD students according to mode of study. Academic Affair Department. Universiti Utara Malaysia.

Wamala, R., Ocaya, B., \& Oonyu, J.C. (2012). Extended candidature and non-completion of a PhD at Makerere university, Uganda. Contemporary Issues in Education Research, 5 (3), 175-184.

Woodward, R. J. (1993). Factors affecting research student completion. In 15th Annual Forum of the European Association for Institutional Research. Turhu, Finland. 